\title{
Review on Public Crisis Management
}

\author{
Jiemin Huang \\ Shenzhen Institute of Information Technology, 2188 Longxiang Boulevard, Longgang District, \\ Shenzhen City, People's Republic of China, 086-518172
}

huang_jiemin819@126.com

Keywords: Public crisis; Management; Mechanism

\begin{abstract}
Many foreign scholars studied for the definition of the crisis. Rosenthal, who believe that the crisis is the basic mechanism of a framework and code of conduct of a serious threat to the social system, and the event at extremely high pressures and uncertainty in the event of the case must be made key decisions. Barton believes that the crisis will cause a potential negative impact of having a large event of uncertainty, such events and their possible consequences for the organization and its staff, products, services, assets and reputation cause some damage. We will find the blank of the literature, and will prepare for further research.
\end{abstract}

\section{Study on Public Crisis Management}

Green said: crisis management feature is the "event has grown to the extent that cannot control," he claimed: "Once the crisis, the time factor is critical to reduce the loss will be an important task." Pointed out the harm crises, run away and time urgency, he believes that the crisis management task is to try to control the situation in the crisis of the loss of control in a certain range, after the situation out of control again to fight for control.

Charles Herman believes that the crisis is a situation state, the fundamental objective of its decision-making body is threatened, before the decision to change the available reaction time is limited, and other decision-making body is also expected.

Chun yu Miao Ling analysis and research before the Great Hanshin Earthquake, the Japanese government's crisis management under the influence of the entire administrative system, legal regulations is relatively mature, but the lack of a rapid response mechanism and unified coordination mechanism, management system construction is lagging behind, causing the Japanese government in the Great Hanshin earthquake failed to play a leading role in the criticism of public opinion. As a lesson and an opportunity to adjust the rights of the Government of Japan to configure relations crisis management, to break the limitations of longitudinal administrative structure, increase the intensity of the crisis management system construction, and achieved remarkable results.

For public crisis management researchers from more practical point of view, the results of a comprehensive researchers, defined as: "the power of the relevant governmental organizations in monitoring, early warning, intervention or control, digestion generate, process and influence the evolution of the crisis taken a series of methods and measures. Crisis is evolving, public crisis management is a dynamic process. Addis Ping believes that it comprises before, during, and afterwards, after four stages of crisis management [1]. The Federal Security Management Committee on Prevention (Prevention), preparation (PreParation), reaction (Response) and recovery (Recovery) that is based PPRR on corrected to slowing (Mitigation), prevention (preparation), the reaction (Response) and recovery (Recovery). Robert Heath proposed 4R model: reduction (Reduction), preparation (Readdiness), reaction (Response), recovery (Recovery) [2].

Many domestic scholars from different perspectives put forward the idea to build public crisis management system. Wang Le fu etc. to "atypical pneumonia" for example, describes an effective crisis management mechanism should include the following aspects: (1) to establish an effective early warning mechanism; (2) the establishment of effective internal coordination mechanisms; (3) 
the establishment of effective intergovernmental machinery and inter-country cooperation and other cooperation mechanisms [3]. BIMONTHLY analysis of defects in our government public crisis management, and crisis management made in accordance with public law, to build a scientific crisis management mechanisms, including three aspects: the establishment of monitoring and early warning of public crisis management mechanism; establish a rapid and efficient emergency response mechanisms; establish rehabilitation repair and conversion mechanisms [4]. Xiao Jinming think, SARS crisis on the ability of the government, the legal system and public morals immediate challenges. In order to successfully deal with the crisis, he proposed three ideas: first, the ability of government reengineering; second, emergency legal arrangements; third, public morality reconstruction [5]. Xue Lan, etc. In the "International Lessons crisis management: the American public health emergency response system as an example", the US public health emergency response system, for example, analysis of the various aspects of its crisis management system, and summarizes summarized some common features foreign crisis management system, for the construction of public crisis management system to provide reference [6]. Wang Xuejun analyzes the various problems our government crisis management system exists, that the government crisis management system should cover the three early-warning systems to prepare crisis, emergency response and crisis recovery after the crisis reconstruction [7]. Huang pointed out that US training occurred during the crisis can be divided into the incubation period, the outbreak period, duration and resolution of four stages, and from the four stages of proposed government crisis management step: treatment of the crisis early warning, crisis control, crisis and reshape the image of the government, he stressed that the government's crisis management should be a sustainable management, and should focus on crisis early warning [8]. Gao Yi believes that crisis management should be taken to reduce the extent of damage of the crisis communication of information, and establish the image of the PR strategy [9]. Xu Gang believes that public relations strategy of crisis management is an important aspect of the government and society to enhance crisis management capability in the government crisis management, public relations should regulate social rumors, shaping the image of the government [10].

In summary, the research scholars of public crisis management focused on the step defining the public crisis, characterized by the principle, through several stages of development, as well as crisis management. After the paper studies before the public crisis management in earthquake disaster occurred, the occurrence of open government information, the study within the scope of the earthquake disaster crisis management of government information disclosure issues.

\section{Study on Government Information Publicity}

Information disclosure system is not there from the beginning of the national produce, it is to break through the conventional administration mysticism and developed, during which there are many sages and insight of expression and opinion on the establishment and development of information disclosure from to an important role.

British Enlightenment thinker John Locke first proposed the principle act of state should be open, he pointed out: "all the rights owned by the government, should be fully serve the community well-being, will not allow willful power to enforce the law must be specifically disclosed only. Public law, people can understand their obligations and comply with the law, in order to maintain social stability, while, in order to ensure that the rulers are not ultra vires. According to the people's democratic sovereignty theory, the government must be timely disclosure of government information, willingly accepted the supervision of authorized persons. Administrative rights from the source point of view, the executive powers enjoyed by the people are from an authorized and

Constitution. People must have a certain way to understand the Government's activities, to participate in the management of state and social management of public affairs, to supervise them, to prevent the alienation of power [11]. Drafters of the United States Declaration of Independence, Jefferson's friend to domestic letter from Paris in 1787 had been a very insightful explanation: "The 
basis of our government from public opinion and therefore should do first is to make the public opinion correctly to avoid making. People mistake it is necessary to provide adequate information on government activities to the people through the press, further studies will have to deliver the news to a wide range of all the people go. [12]

$\mathrm{Xu}$ Hua once said: "If the Government does not have a National IFAP, or lack of access to information in this way, then it will either be a prelude to a farce or a tragedy, it could both [13]." President of the American Association of newspaper Editors freedom of information Commission James Russell in "freedom or Confidential," a book induction, the right to information is a comprehensive civil rights. Nuoman $\mathrm{Mu}$ Qiao Williams, he noted that most ordinary people can only get the message or cause and effect of government affairs and events from the popular media was able to form my own opinion. Only in a democratic society when the public can get full and impartial information to make choices in order to reflect the conscious choice of democracy and freedom, only to be called a true democracy.

Chinese scholars about the government information disclosure issues were also a more comprehensive study, we have made some achievements. PR China in our government affairs practice and exploration in the Foreign Open Administration System were compared and analyzed the practice of public administration, put forward China Open Government Information Expert advice [14]. Zhang Ming jie in the open government a government information disclosure Legal System systematically expounded government information disclosure legal system of historical development, theoretical foundation, basic system configuration, and the status of our government information disclosure system, problems and countermeasures [15]. Liu Heng in the book, "Government Information Disclosure System" in the proposed disclosure of government information refers to the state administrative organs and laws, rules and regulations authorized and commissioned by organizations in the course of the exercise of state administration authority through legal forms and procedures initiative the government information to the public or disclosed by an application to a specific individual or organization system, "the Guangzhou municipal government information disclosure regulations" as an example, to explore the Chinese government information disclosure legislation [16].

\section{Review}

In summary, the research scholars of FOI focused on the following aspects: the need for open government information, content, inspiration, and advice now, these are mainly general discussion of open government information theory point of view similar. The earthquake disaster in China FOI development, studying and learning aspects of the progress, problems, and experiences of other countries are few. In this paper, these aspects of the earthquake disaster in the government information disclosure issues in-depth and meticulous research, put forward some of their own point of view for the earthquake disaster in China Open Government Information gradual improvement and healthy development, hoping to promote the government comprehensive, timely and accurate, transparent the information disclosure.

\section{Reference}

[1] Si Ya Ping. The public crisis management system research. Intellectual property press. 2008:4

[2] Robert Heath. Crisis management. Citic publishing house. 2001:18

[3] Wang Le Fu. Public crisis management system in the case of SARS-Chinese administrative management. 2003, (7): 15

[4] Xing-jun wu. The basic features of public crisis management and mechanism construction. East China economic management. 2004, (3) : 26

[5] Jin-ming xiao. Reflection on SARS crisis - the government reengineering, the legal system 
construction and the moral reconstruction. China's administrative management. 2003, (7) : 19

[6] Xue. International crisis management - public health emergency response system in the United States, for example. China's administrative management. 2003, (8) : 16

[7] Wang Xue Jun. response and recovery: the construction of the government crisis management system in contemporary China. Theoretical exploration. 2004, (4) : 20

[8] Huang Xun beauty. Analysis of the government's crisis management. Guangming daily. 2004

[9] Gao Shi yi. The role of media in the government crisis management. In the evaluation of the net. http://www. China - review. Com/index. The asp.

[10] $\mathrm{Xu}$ Gang. Research on public relations in the government crisis management. China's administrative management. 2004, (5) : 29

[11] Shi an bin. Crisis communication and press release. Southern daily press. 2004:49

[12] Michael emory. History of the United States. The Chinese people's university press. 2004:131-132

[13] Xu Hua. Sichuan earthquake documentary. Huacheng press. 2008:54

[14] Zhou Han Hua. Practice and exploration of our country's government. China legal system publishing. 2003:15

[15] Gibson ca. Legal system of open government, the government information disclosure research. China politics and law university press. 2003:18

[16] Liu Heng. The government information publicity system. China social science press. 2004:22 